\title{
The duration of fixed exchange rate regimes
}

\author{
Sébastien Wälti* \\ Trinity College Dublin
}

August 2005

\begin{abstract}
This paper studies the survival of fixed exchange rate regimes. The probability of an exit from a fixed exchange rate regime depends on the time spent within this regime. In such a context durations models are appropriate, in particular because of the possible non-monotonic pattern of duration dependence. Non-parametric estimates show that the pattern of duration dependence exhibits non-monotonic behaviour and that it differs across types of economies. This behaviour persists when we control for time-varying covariates in a proportional hazard specification. We conclude that how long a regime has lasted will affect the probability that it will end, in a non-monotonic fashion.
\end{abstract}

JEL Classification: F30, F31, F41.

Keywords: Exchange rate regime, currency crisis, regime transition, duration models, survival analysis.

*Sébastien Wälti, Department of Economics, Trinity College Dublin, Dublin 2, Ireland. Email: waltis@tcd.ie. Phone: +35316081041. Fax: +35316772503. I am grateful to Hans Genberg, Roberto Rigobon and Charles Wyplosz for insightful comments and suggestions. All remaining errors are mine. 


\section{Introduction and motivation}

The widespread wave of currency and financial crises that has affected developed and emerging market economies during the last decade has brought the issue of optimal exchange rate policy back to the forefront of the research agenda in international macroeconomics. In particular, much attention has been given to exits from fixed to flexible exchange rate regimes, their nature, as well as their macroeconomic, financial and institutional determinants. Most empirical studies make use of discrete-choice econometric specifications, whereby the dependent variable takes a value of unity whenever an exit occurs, and zero otherwise.

This paper is about the survival of fixed exchange rate regimes. We argue that the time spent within a given regime is likely to determine the probability that a regime will end. Klein and Marion (1997) and Duttagupta and Otker-Robe (2003) introduce duration as an explanatory variable in a logit specification. The statistical significance of the attached regression coefficient indicates that time matters, and its sign whether it contributes positively or negatively to the probability of an exit. This approach remains limited on conceptual and analytical grounds and a duration model will be more appropriate.

At a conceptual level duration analysis deals directly with the conditional probability of an event taking place, rather than with its unconditional probability. The key question is: "What is the probability that a given regime will end at time $t+1$, given that it has lasted up to time $t$ ?" The natural way of thinking about the probability that a regime will end at some point in the future when we believe that the time spent within the regime affects this same probability is in terms of successive rounds. Suppose that a regime starts in period 1. In period 1 , we will consider the probability that the regime will end in period 2 . In period 2, we will consider the probability that the regime will end in period 3, conditional on the fact that the regime has lasted up to period 2 . In period $t>2$, we will consider the probability that the regime will end in period $t+1$, conditional on the fact that the regime has lasted up to period $t$. If we believe that duration is important then the probability of an exit at some point in the future is naturally considered as a sequence of simpler events. 
This natural view of the problem emphasizes conditional probabilities, not unconditional ones.

At an analytical level duration models allow for the easy characterization of duration dependence. If we introduce duration as an explanatory variable in a logit regression and look at the sign of the estimated coefficient, the probability of an exit either increases or decreases with duration. In reality, however, there could be a non-monotonic relationship between the probability of an exit and the duration of a regime. It could be that the probability of an exit increases at shorter durations but that it decreases beyond a certain time threshold. Moreover, duration analysis can easily cope with the problem of censoring. It is likely that some regimes will not be terminated by the end of the sample period. At the time of writing Hong Kong still has a currency board arrangement. Consequently, the observation for Hong Kong will be right-censored. Such observations should be taken into account.

This paper makes use of duration models to study duration dependence across types of countries using the non-parametric Kaplan-Meier estimator. Moreover, we estimate a semi-parametric proportional hazard specification that allows for time-varying independent variables in order to identify the determinants of the probability of an exit. Regime durations are constructed on the basis of the de facto classification of exchange rate regimes proposed by Reinhart and Rogoff (2004).

The results show a clear non-monotonic pattern of duration dependence. The nonparametric Kaplan-Meier estimator reveals that the relationship between the probability of an exit and the time spent within a regime differs significantly across types of countries. The semi-parametric approach shows that inflation, openness and current account balance affect the conditional probability of an exit. Nevertheless, the pattern of duration dependence remains non-monotonic even after introducing time-varying covariates. In other words, it seems that the probability of an exit from a fixed exchange rate regime is affected by the time spent within this regime, other things being equal.

The paper is organised as follows. Section 2 reviews the literature on exits from fixed exchange rate regimes. Section 3 introduces important concepts for duration analysis and 
presents the estimation methods. Section 4 deals with the identification of regimes, exits and regime durations. It discusses the various classifications of exchange rate regimes that are available and motivates our particular choice. We also describe the explanatory variables that are included in the estimation of the semi-parametric model. Section 5 provides the results and section 6 concludes.

\section{Review of the literature}

Some recent empirical work studies the determinants of exits from fixed exchange rate regimes. These studies differ along several dimensions: exchange rate regime classification, identification of an exit, type of exit, time period, sample of countries, econometric methodology, and explanatory variables.

The source of data varies greatly across studies. In turn, the procedure for the identification of an exit depends largely on the data that are used. Klein and Marion (1997) focus on official end-of-month exchange rates retrieved from the IMF's International Financial Statistics and define an exit as the end of a period during which there exists a particular fixed value of the currency with respect to the U.S. dollar. Tudela (2004) combines data for the nominal exchange rate, the short-term interest rate and international reserves to build an indicator variable of exchange market pressure. In this context, an exit occurs whenever the constructed indicator exceeds a given threshold value, thereby ending a tranquil period. Setzer (2004) uses the de facto exchange rate regime classification proposed by Levy-Yeyati and Sturzenegger (2005).

These three studies do not really focus on exits from fixed exchange rate regimes. The first two are more related to the literature dealing with the determinants of currency crises, along the lines of Eichengreen, Rose and Wyplosz (1995), and with the quest for early warning indicators of such crises, such as Kaminsky, Lizondo and Reinhart (1998). Moreover, as we discuss below, the de facto classification used by Setzer (2004) does not identify regimes properly. Looking at the stability of the exchange rate and other variables over time may identify an exit when some parameter describing the exchange rate regime 
changes, while the underlying regime remains the same. For example, these studies would capture an exit when the central parity of a target zone arrangement is devalued to a new level. One parameter of the regime changes, but the regime itself has not changed: it is still a target zone! The classification proposed by Reinhart and Rogoff (2004) and used by both Asici and Wyplosz (2003) and Detragiache, Mody and Okada (2005) deals with this problem explicitly. Reinhart and Rogoff (2004) focus on a five-year window to identify exchange rate regimes on the basis of market-determined nominal exchange rates. Taking such a perspective allows for a better definition of regime changes as opposed to changes in some regime parameter.

The sample of countries varies across studies, including either OECD countries, or Latin American countries, or a selection of developed, emerging market and other economies, or all countries. Most of the literature, e.g. Detragiache, Mody and Okada (2005), makes use of logit or probit regressions, whereby the dependent variable takes a unit value whenever there is an exit. Masson and Ruge-Murcia (2003) estimate time-varying transition probabilities, which are specified as nonlinear functions of explanatory variables. There are few papers that rely on duration models. Tudela (2004) studies the determinants of currency crises. Meissner (2002) uses duration analysis to explain the decision of countries to join the classical gold standard. Sosvilla-Rivero, Maroto-Illera and Perez-Bermejo (2002) focus on the determinants of realignments and exits within the ERM. Blomberg, Frieden and Stein (2004) and Setzer (2004) make use of a duration approach. However, Setzer (2004) focuses on a classification of regimes that remains inadequate and that is only available on a yearly basis while some regimes last less than one year. Blomberg, Frieden and Stein (2004) focus only on Latin American and Caribbean countries and rely on officially reported exchange rates in their definition of exchange rate regimes while many countries have introduced dual exchange rates and/or parallel markets.

Independent variables are usually taken from two strands of literature: the prediction of currency crises, and optimum currency area criteria. These variables can be classified under three main headings: macroeconomic variables, such as the real exchange rate, openness, trade concentration, fiscal policy, monetary policy, inflation, growth; financial variables, 
such as international reserves, foreign assets, domestic credit, foreign direct investment; and institutional and political variables, such as regular and irregular executive transfers, IMF program, corruption, political freedom. Moreover, two studies using logit regressions include the duration of the exchange rate peg as a determinant of the likelihood of an exit. Some explanatory variables are significant across most studies: inflation, competitiveness as measured by the evolution of the real exchange rate, and openness.

The vast majority of existing research ignores the issue of censoring systematically, except for those papers using duration models. Suppose that we are focusing on exits between time $t_{1}$ and time $t_{2}$. We will observe some exits between $t_{1}$ and $t_{2}$ without being able to compute the duration when the regime has started before time $t_{1}$. Conversely, some regimes will still be in place after time $t_{2}$, so that we do not observe an exit and are again not able to compute a duration. The literature on duration models recognizes this issue as being very important and proposes ways to take censoring into account. To our knowledge, the studies which include duration as an explanatory variable in a logit framework disregard the problem. Duttagupta and Otker-Robe (2003) exclude incomplete spells explicitly. For example, Hong Kong is excluded from the analysis since its currency board regime is still in place as we write: there is no exit.

\section{Econometric methodology}

We define the nonnegative random variable $T$ as the duration (or spell) during which a fixed exchange rate regime is in place ${ }^{1}$. The unconditional probability that the spell will be shorter than some given value $t$ is given by the cumulative distribution function, written as $F(t)=\operatorname{Pr}(T<t)$. The associated probability density function is written as $f(t)$. Duration analysis makes use of the reverse cumulative distribution function, referred to as the survivor function, which is written as $S(t)=1-F(t)$.

We will estimate the hazard function which captures the conditional probability that the spell will terminate at time $T=t$, given that it has survived until time $t$. It is given

\footnotetext{
${ }^{1}$ This presentation relies on Kiefer (1988).
} 


$$
\begin{aligned}
\lambda(t) & =\lim _{d t \rightarrow 0} \frac{\operatorname{Pr}(t<T<t+d t \mid T \geq t)}{d t} \\
& =\frac{f(t)}{S(t)}
\end{aligned}
$$

Clearly, both representations in terms of the hazard function and the probability density function contain exactly the same information. However, the hazard function is useful in so far as its shape provides a definition of duration dependence. Positive duration dependence exists at the point $t^{*}$ when $d \lambda(t) / d t>0$ at $t=t^{*}$. The probability that a regime will end increases as the regime increases in length of time. Conversely, negative duration dependence exists at the point $t^{*}$ when $d \lambda(t) / d t<0$ at $t=t^{*}$. The condition that $d \lambda(t) / d t=0$ for every $t$ defines a so-called memoryless system. Clearly, it is possible that the hazard function evolves with time in a non-monotonic fashion alternating between positive and negative duration dependence.

There are different approaches to estimating the hazard function. The Kaplan-Meier estimator is a non-parametric approach. The random spell is written as $T^{*}$ in the absence of censoring. The censoring time is $C$. Then, the observed random variable is $T=$ $\min \left(T^{*}, C\right)$. Suppose that there are $k$ completed durations in our sample of size $n$, where $k<n$ since some observations are censored, and because two or more observations can have the same duration. We define a variable $\delta$ that takes the value 1 if the observation is censored, and zero otherwise. We assume that if $T=t$ and $\delta=1$, censoring happens immediately after time $T$. We can order the completed durations from smallest to largest, $t_{1}<t_{2}<\ldots<t_{k}$. We denote the number of durations that end at time $t_{i}$ by $d_{i}$, and the number of durations censored between $t_{i}$ and $t_{i+1}$ by $m_{i}$. The risk set is the set of durations that are eligible to end at time $t_{i}$ and is defined as

$$
n_{i}=\sum_{j \geq i}^{k}\left(m_{j}+d_{j}\right)
$$

The scalar $n_{i}$ is really the number of durations neither completed nor censored before 
duration $t_{i}$. The probability of ending a regime in the interval $t+d t$ given that the spell lasts up to time $t$ is given by

$$
\widehat{\lambda}\left(t_{i}\right)=\frac{d_{i}}{n_{i}}
$$

Parametric estimation requires an assumption about the underlying distribution of the random variable $T$. Suppose that the distribution of durations is known up to a vector of parameters $\theta$. The density of a duration is $f(t, \theta)$. The only information available on a censored duration at time $t_{j}$ is that this duration was at least $t_{j}$. The contribution to likelihood is then given by the value of the survivor function, $S\left(t_{j}, \theta\right)$. We can again construct a dummy variable $\delta$, taking a value of unity when the observation is censored and zero otherwise. The log-likelihood function is given by

$$
\ln L^{*}(\theta)=\sum_{i=1}^{n}\left(1-\delta_{i}\right) \ln f\left(t_{i}, \theta\right)+\sum_{i=1}^{n} \delta_{i} \ln S\left(t_{i}, \theta\right)
$$

which can be rewritten in terms of the hazard and integrated hazard functions

$$
\ln L^{*}(\theta)=\sum_{i=1}^{n}\left(1-\delta_{i}\right) \ln \lambda\left(t_{i}, \theta\right)-\sum_{i=1}^{n} \Lambda\left(t_{i}, \theta\right)
$$

In practice, the sample of durations is rarely homogeneous and is affected by various explanatory factors. A convenient specification is the proportional hazard $(\mathrm{PH})$ specification which is written as

$$
\begin{aligned}
\lambda\left(t, x, \beta, \lambda_{0}\right) & =\lambda_{0}(t) \phi(x, \beta) \\
& =\lambda_{0}(t) \exp \left(x^{\prime} \beta\right)
\end{aligned}
$$

where $x$ is a vector of explanatory variables, and $\beta$ is a vector of unknown parameters to be estimated. The so-called baseline hazard $\lambda_{0}$ corresponds to the case where $\phi()=$. and represents the hazard function for the mean individual. Explanatory variables affect the hazard function by multiplying the baseline hazard by a time-invariant factor $\phi($.$) .$ This specification is convenient for two reasons. First, to the extent that both $\lambda($.$) and \lambda_{0}$ 
are conditional probabilities, $\phi($.$) will be nonnegative and there is no necessary restriction$ on the vector of coefficients $\beta$. Second, we can interpret the estimated coefficients as the constant proportional effect of $x$ on the conditional probability $\lambda($.$) .$

In many practical applications, the underlying distribution is unknown. However, it is still possible to make no arbitrary assumption about the form of this distribution and resort to semi-parametric estimation. For the sake of the exposition, suppose that all $n$ observations are uncensored. We can order observed durations from smallest to largest, $t_{1}<\ldots<t_{n}$. The conditional probability that the first observation concludes a spell at time $t_{1}$, given that all of the $n$ durations could have ended at time $t_{1}$, is

$$
\frac{\lambda\left(t_{1}, x_{1}, \beta, \lambda_{0}\right)}{\sum_{i=1}^{n} \lambda\left(t_{1}, x_{i}, \beta, \lambda_{0}\right)}
$$

This quantity is the contribution of the first observation to partial likelihood. The numerator is the hazard for the individual whose spell completes at time $t_{1}$, while the denominator is the sum of the hazards for individuals whose spells could have ended at time $t_{1}$. If we adopt the specification $\lambda\left(t, x, \beta, \lambda_{0}\right)=\lambda_{0}(t) \phi\left(x_{1}, \beta\right)$ this ratio becomes

$$
\frac{\lambda_{0}(t) \phi\left(x_{1}, \beta\right)}{\lambda_{0}(t) \sum_{i=1}^{n} \phi\left(x_{i}, \beta\right)}=\frac{\phi\left(x_{1}, \beta\right)}{\sum_{i=1}^{n} \phi\left(x_{i}, \beta\right)}
$$

Only the order of completed durations provides information on the unknown coefficients. The baseline hazard $\lambda_{0}$ cancels out and therefore, we do not have to make an assumption on its underlying distribution. It is recovered from the partial likelihood estimation. In general, the log-likelihood function is obtained as

$$
\ln L^{*}(\beta)=\sum_{j=1}^{n}\left[\ln \phi\left(x_{j}, \beta\right)-\ln \sum_{i=j}^{n} \phi\left(x_{i}, \beta\right)\right]
$$

We shall proceed in two steps. Firstly, we estimate the hazard function using the non-parametric estimator for the whole sample and sub-samples of the data. This graphical evidence can illustrate differences in duration dependence across types of economies. Secondly, we make use of a proportional hazard specification to account for time-varying explanatory variables to assess how these affect the conditional probability that a given 
exchange rate regime will end. Indeed, it may be that the pattern of duration dependence shown by the non-parametric estimator is explained by the time-varying behaviour of explanatory factors. In the extreme, we could observe that the time spent within a fixed exchange rate regime could have no effect on the conditional probability of an exit, once that the appropriate time-varying factors are taken into account.

\section{Data}

The identification of a duration requires the definition of a time origin, a time scale, and an event that ends the duration. We have argued that most studies do not deal with exchange rate regimes but rather with spells of exchange rate stability. Focusing exclusively on the behaviour of the nominal exchange rate or on an index of exchange market pressure may lead us to conclude that a regime changes, when in fact only some parameter describing this regime changes. Therefore, we need a classification of exchange rate regimes that takes this problem into account.

\subsection{Exchange rate regime classification}

Most empirical studies on exchange rate regimes have relied on the classification available from the IMF's Annual Report on Exchange Arrangements and Exchange Restrictions which is constructed according to official declarations made by national governments once a year. It has been criticized, in particular on the ground that countries do not always do what they say they are doing. Countries that declare a flexible exchange rate regime often intervene in the foreign exchange market to such an extent that in practice there is little difference in the behaviour of the nominal exchange rate relative to countries that have explicit fixed exchange rates (Calvo and Reinhart, 2002). Moreover, repeated devaluations of fixed exchange rate parities, especially in countries prone to high inflation, make the exchange rate regime look like a flexible arrangement.

Recent new classifications have been constructed to address the shortcomings of the IMF's de jure classification. Bubula and Otker-Robe (2002) combine qualitative and quan- 
titative information to provide a monthly classification that covers all IMF members since 1990. Most information is obtained through bilateral consultation discussions with member countries, as well as through regular contacts with IMF desk economists, supplemented by other sources of information such as press reports, news articles, and other relevant papers, and supported by an analysis of the observed behaviour of the nominal exchange rate and international reserves. Ghosh, Gulde and Wolf (2002) construct an annual index of exchange rate flexibility that is mapped into a discrete number of regime categories according to the relative frequency distribution of the de jure annual classification.

Some approaches disregard qualitative information altogether and rely exclusively on observed macroeconomic time series. Shambaugh (2004) constructs a binary classification of fixed and flexible regimes, on the basis on the monthly behaviour of the nominal exchange rate. A fixed exchange rate regime is identified if the exchange rate has remained within \pm 2 percent bands against the base currency during the year. Levy-Yeyati and Sturzenegger (2005) make use of a cluster analysis to classify countries into different regime categories according to the volatility of exchange rates and international reserves. A fixed exchange rate regime is typically characterized by volatility in international reserves in order to stabilize the exchange rate at the announced parity. In contrast, floating exchange rates feature significant exchange rate volatility while foreign exchange reserves remain rather stable.

Reinhart and Rogoff (2004) address two important issues that other studies have not examined. Firstly, the existence of dual or multiple exchange rates, and/or parallel markets, means that market-determined exchange rates can differ significantly from officially reported exchange rates. Failing to look at market-determined rates leads to misleading perceptions about the underlying monetary policy and the ability of the economy to adjust to shocks. Secondly, other classifications identify short-term spells of exchange rate stability within a regime rather than regimes themselves. The realignment of a central parity in a target zone would be captured as a regime change in other classifications, when in fact only a parameter of the regime changes. Reinhart and Rogoff (2004) use historical chronologies to assess whether there are dual or multiple exchange rates, and/or paral- 
lel markets. They use a battery of descriptive statistics applied to the behaviour of the market-determined nominal exchange rate and classify countries according to fourteen categories on a monthly basis. They consider a five-year window in order to avoid focusing on short-term spells. The new classification differs significantly from the officially reported exchange rate arrangements.

We adopt the de facto classification constructed by Reinhart and Rogoff (2004). It is available at a monthly frequency over a long time period, avoids identifying short spells of exchange rate stability as regimes, takes account of the fact that countries may have dual or multiple exchange rates, and/or parallel markets, and is not based on official declarations but rather on the actions of monetary authorities.

\subsection{Definition of exits and durations}

The time origin for each duration is defined as the first month during which the classification shows any type of a fixed exchange rate regime. We define an exit from a fixed to a flexible exchange rate regime as a shift from any fixed category to managed floating, free floating or free falling. The sample period extends from January 1974 until December 2001. Each duration corresponds to the number of months from the time origin until the ending event. If a regime is still in place by December 2001 we count the number of months until that date and register the observation as being censored.

This operational definition runs into a problem of left truncation. A number of exchange rate regimes will start before January 1974. This does not affect the estimations of nonparametric and semi-parametric specifications. The Kaplan-Meier calculation of the hazard function makes use of the number of regimes that are eligible to fail, and this number will capture the fact that these regimes are not at risk of failing (since they all survived) until they come under observation. The semi-parametric approach uses only observations at times of failure. The simple fact that a regime is observed in January 1974 means that it did not fail before. This is true for all regimes observed in January 1974, so none of these regimes can have failed before that date. Hence, we would not have any observation to contribute to partial likelihood. 


\subsection{Explanatory variables}

The proportional hazard model allows for time-varying explanatory variables. We select these variables on the basis of empirical studies dealing with the determinants of the onset of currency crises, and with the factors underlying the optimal choice of an exchange rate regime $^{2}$. Macroeconomic variables include inflation, economic growth, openness, current account balance, budget balance, unemployment, the real exchange rate, and a dummy variable for a banking crisis. Financial variables consist of the rate of growth of international reserves and the level of financial development. Finally, institutional factors include the level of central bank independence, the quality of institutions (proxied by an index of political rights) and a dummy variable for the presence of capital controls.

The partial likelihood estimation procedure implies that we will use data only at times of failures. Since our durations are calculated in months, we should use monthly values of explanatory variables at times of failures. However, we could not collect data at the monthly frequency for each time-varying covariate. When such data are not available, we use the value for the year before that which contains the month during which a failure occurs. This choice is clearly arbitrary. However, it is likely to minimise the possible endogeneity of macroeconomic and financial variables. An exit represents a significant change in the structure of the economy and many variables are likely to respond to such a change.

\section{Results}

This section presents our results in three steps. We start with some descriptive statistics on the computed durations and calculate estimates of the hazard function using the KaplanMeier estimator. Finally, we show the estimates of the proportional hazard model.

\footnotetext{
${ }^{2}$ We discuss the source and measurement of our variables in the appendix.
} 


\subsection{Descriptive analysis}

The full sample between January 1974 and December 2001 yields 87 durations for 58 countries. Fifty-one observations correspond to regimes that have ended before or in December 2001, and the remaining 36 observations are right-censored. We disaggregate this number between developed and emerging economies ${ }^{3}$. Table 1 provides summary statistics (expressed in months) on durations for the two different types of countries.

Table 1: Summary statistics for durations (expressed in months)

\begin{tabular}{||l||c|c|c||}
\hline \hline & Full sample & Developed & Emerging \\
\hline \hline Obs & 87 & 33 & 54 \\
\hline Failed & 51 & 16 & 35 \\
\hline Censored & 36 & 17 & 19 \\
\hline \hline Mean & 140 & 188 & 111 \\
\hline Median & 105 & 196 & 78 \\
\hline Stdev & 176 & 126 & 99 \\
\hline Min & 3 & 3 & 3 \\
\hline Max & 336 & 336 & 336 \\
\hline \hline
\end{tabular}

Regimes can last for a very long period of time. Fourteen countries exhibit a fixed exchange rate during our entire sample. Regimes can also be very short, lasting three months. The mean for the full sample of countries equals 140 months, about 12 years. This number is in line with Husain, Mody and Rogoff (2004), and contradicts previous studies on the evolution of exchange rate regimes. Klein and Marion (1997) report a mean duration of 32 months. The difference reflects the underlying definition of an exchange rate regime. We focus on exchange rate regimes whereas previous studies focus on shortterm exchange rate spells. Moreover, fixed exchange regimes in the developed world last

\footnotetext{
${ }^{3}$ Developed economies include Australia, Austria, Belgium, Canada, Cyprus, Denmark, Finland, France, Germany, Greece, Hong Kong, Iceland, Ireland, Italy, Japan, Netherlands, New Zealand, Norway, Portugal, Singapore, Slovenia, Spain, Sweden, Switzerland, United Kingdom, and United States. Emerging markets include Argentina, Brazil, Bulgaria, Chile, China, Colombia, Czech Republic, Ecuador, Egypt, Estonia, Hungary, India, Indonesia, Israel, Jordan, Korea, Latvia, Lithuania, Malaysia, Mexico, Morocco, Pakistan, Peru, Philippines, Poland, Romania, Russia, Slovak Republic, Thailand, Turkey, Uruguay, and Venezuela.
} 


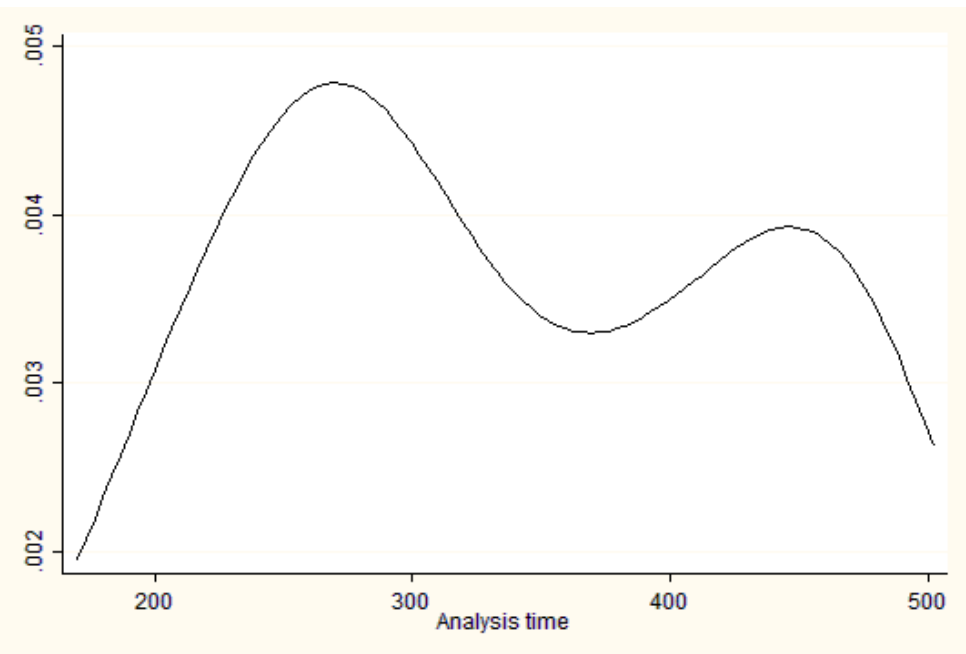

Figure 1: Estimated hazard function, all countries

significantly longer than those of emerging market economies ${ }^{4}$.

\subsection{Non-parametric estimation}

Figure 1 presents the estimated hazard function obtained with the Kaplan-Meier estimator for the full sample. A clear non-monotonic pattern of duration dependence appears. More precisely, it alternates between increasing and decreasing parts. Therefore, duration dependence cannot be qualified as being either positive, or negative: it depends upon survival time. Probit and logit regressions will not be able to capture the effect of duration on the probability of an exit adequately. Furthermore, it remains difficult to provide for an interpretation of such duration dependence. It could arise from the fact that credibility is only gradually achieved after the adoption of a fixed exchange rate regime. The conditional probability of an exit would rise initially. Conditional on survival up to a certain time threshold, however, this probability would then start declining.

Our descriptive analysis shows that regime durations vary across types of countries.

\footnotetext{
${ }^{4}$ Clearly, our summary statistics are computed under the implicit assumption that regimes start in January 1974 or later, and that they end in December 2001 or before. This is obviously misleading since some observations are left-truncated and others are right-censored. However, these numbers indicate some country heterogeneity and overall trends which are useful information for the construction of the semi-parametric specification.
} 


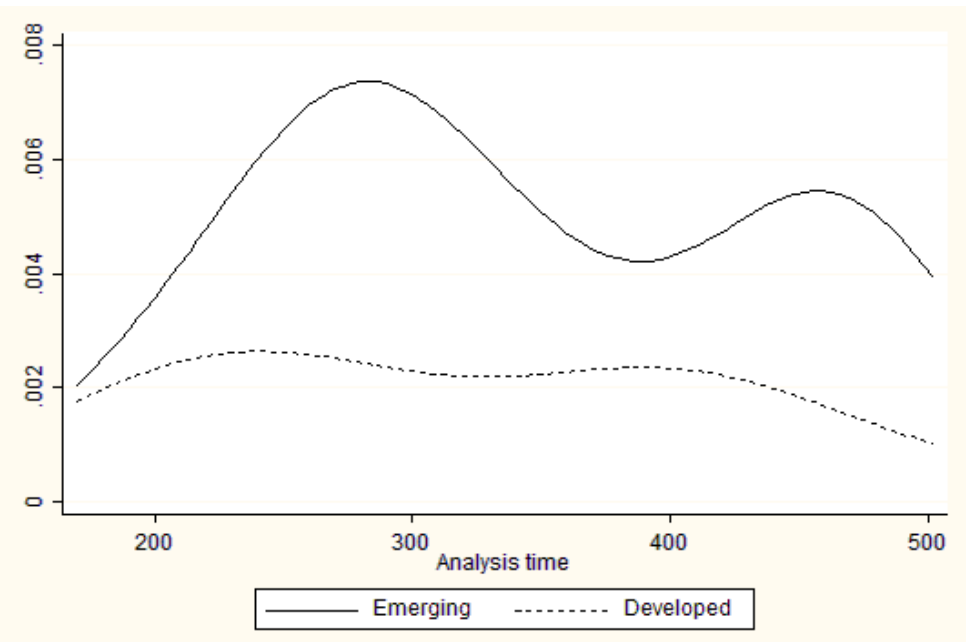

Figure 2: Estimated hazard functions, by country type

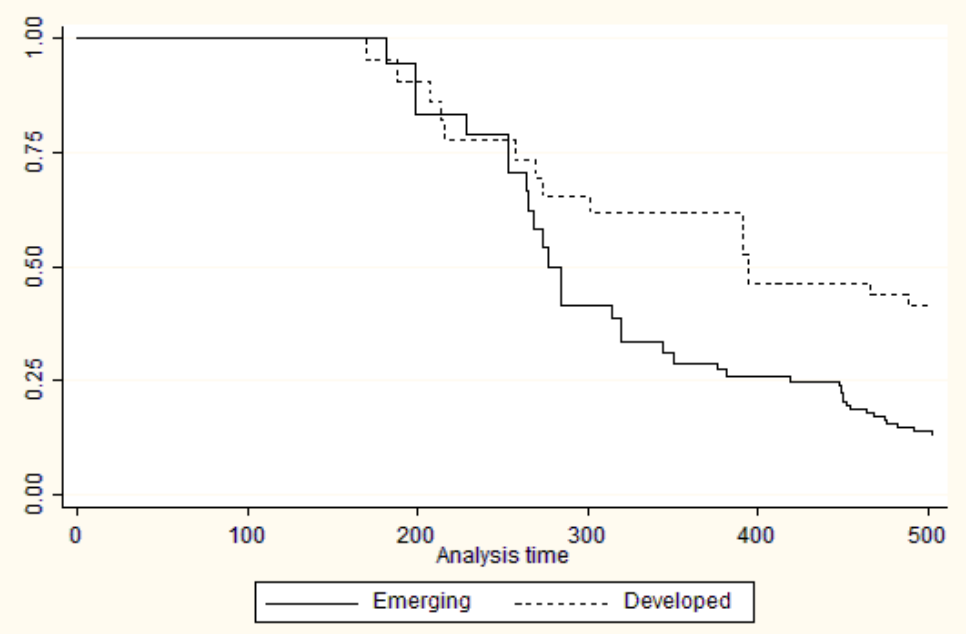

Figure 3: Estimated survivor functions, by country type 
Figure 2 estimates separate hazard functions and shows that there are pronounced differences in the shape of the hazard functions depending on country type. Developed economies exhibit almost no duration dependence. Emerging market economies are characterised by a higher hazard function with a non-monotonic pattern of duration dependence. Figure 3 presents estimates of the survivor functions and confirms this evidence. A log-rank test of the equality of survivor functions rejects the null hypothesis at the $1 \%$ level.

The bipolar hypothesis of exchange rate regimes claims that in a world of highly integrated financial markets, fixed exchange rate regimes are not sustainable in the long run and will inevitably collapse at some point. In terms of duration dependence, the hypothesis can be interpreted as positive duration dependence. In other words, the conditional probability of an exit will not decrease over time. Our results for emerging markets could suggest that this hypothesis is not supported by the data since a significant portion of the hazard function is decreasing. However, such a conclusion is doubtful for at least two reasons. Firstly, we should control for other factors which are likely to affect the viability of a fixed exchange rate regime, such as the degree of openness of the economy and the respective stance of fiscal and monetary policies. Secondly, the bipolar hypothesis holds that countries which are financially integrated will move to the corners, either hard pegs or floats. Our aggregation of hard and intermediate regimes together allows us to examine the move from fixing to floating only. Future research should disaggregate the data across different types of pegging arrangements.

Finally, we examine the hazard function that results when censored observations are excluded. The sample reduces to 51 observations. Figure 4 separates between types of countries and shows that both functions indicate (close to) positive duration dependence at all times, in particular for developed economies. Therefore, excluding censored observations affects the nature of duration dependence dramatically. Moreover, and not surprisingly, the estimated values for the hazards increase, reflecting the bias that obtains when the problem of right-censoring is ignored. 


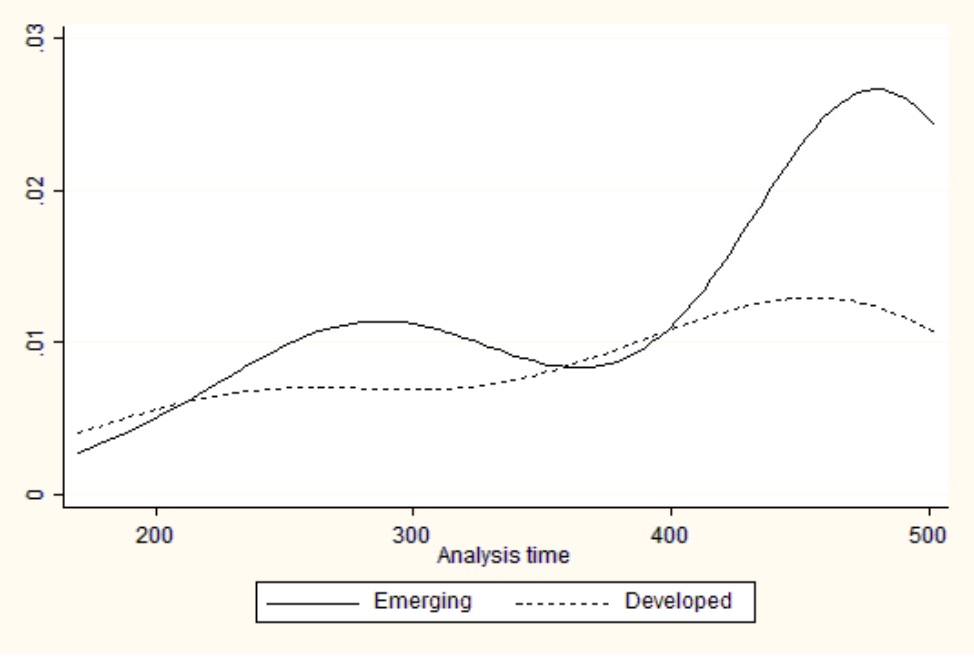

Figure 4: Estimated hazard functions, by country type, only observed exits

\subsection{Semi-parametric estimation}

Non-parametric estimations show a non-monotonic pattern of duration dependence that varies across types of countries. Consequently, we control for country-specific time-varying explanatory variables by estimating a proportional hazard model. The baseline specification (I) includes selected macroeconomic and financial variables, namely inflation, growth, international reserves, openness, the current account, budget balance and the rate of unemployment. Other specifications (II) to (VI) test for the robustness of the results arising from our initial specification by including alternatively capital controls, a banking crisis index, the degree of financial development, political rights, changes in the real exchange rate, central bank independence, and a country dummy variable. In the end, we are trying to explain the time-varying feature of duration dependence and see whether including explanatory variables affects this feature. Table 2 presents the results. We report the number of observations and the p-value of a chi-squared test for the overall validity of the model. The null hypothesis that the coefficients are jointly zero is always strongly rejected.

The coefficients for the degree of openness and current account balance are always negative and significantly different from zero. A greater degree of openness to the rest of the world and a stronger current account correspond to a reduced probability of an exit. 


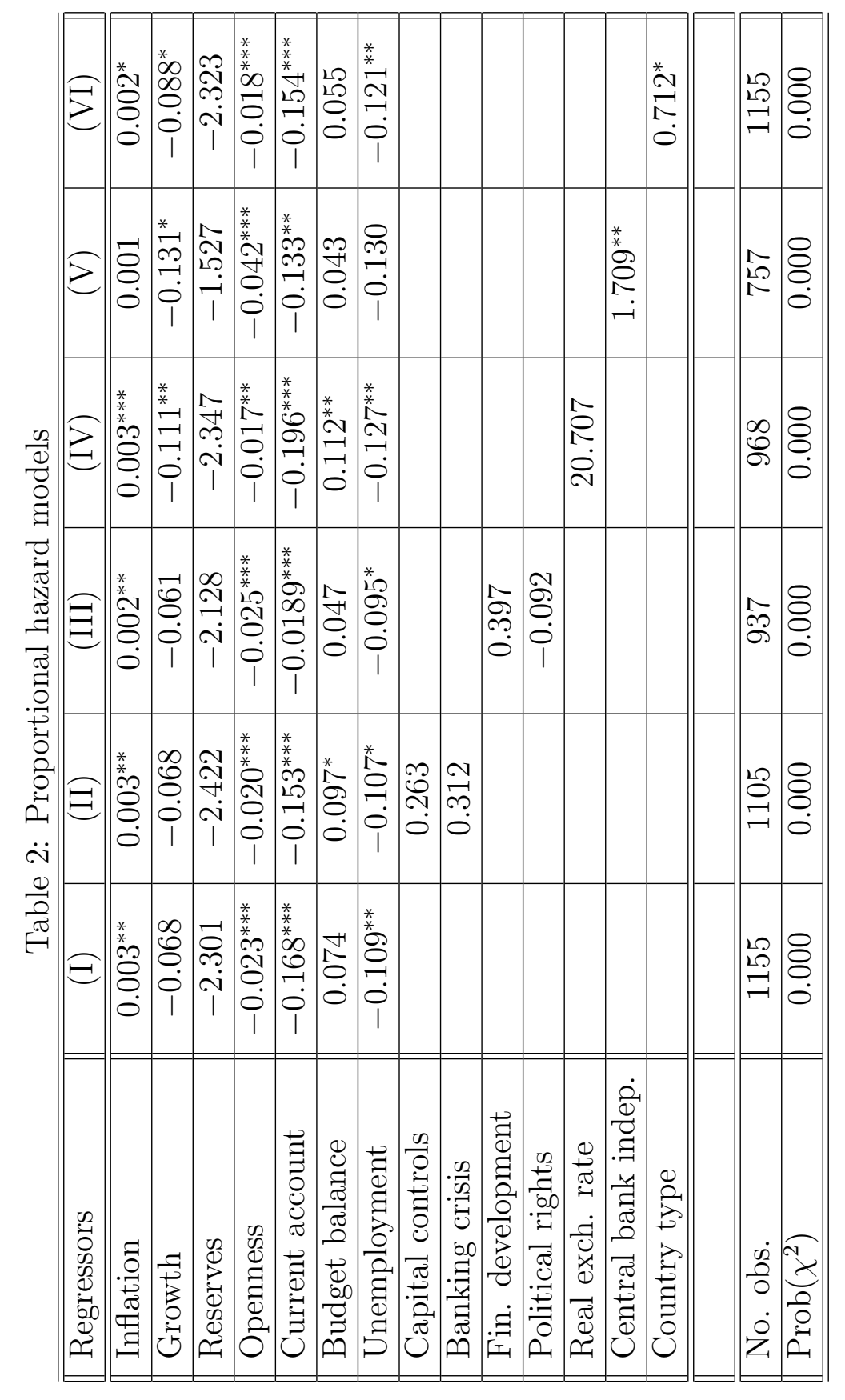


The coefficient on the rate of inflation is always positive and almost always significant, except when an index of central bank independence is included. A greater degree of governor turnover (less central bank independence) implies an increasing probability of an exit. The fact that we cannot reject the null hypothesis that the coefficient on inflation is zero may be attributed to the well-known relationship between inflation and central bank independence. Economic growth matters weakly in some specifications, while the rate of growth of international reserves remains insignificant in all specifications. Budget balance appears to be significant in two models only. The coefficients on the rate of unemployment is usually significant but carries a surprising negative sign. We would have expected that a greater rate of unemployment would lead policymakers to adopt a floating exchange rate regime, thereby reducing the survival of fixed exchange rate regimes.

Our results show that the conditional probability of an exit is not significantly affected by the presence of capital controls, the occurrence of a banking crisis, the degree of financial development, the overall quality of institutions within the country and the behaviour of the real exchange rate. However, we note that most coefficients on these variables carry the expected sign. For example, the incidence of a banking crisis would correspond to an increased probability of an exit, other things being equal. In general, the baseline specification captures most of country heterogeneity. A dummy variable for an emerging market country is significant at the $10 \%$ level only.

Partial likelihood estimation allows for the retrieval of the baseline hazard function. Figure 5 presents a smoothed version of this function and shows that even after having controlled for macroeconomic, financial and institutional variables, the shape of the hazard function remains relatively unaffected. It still remains that it increases initially and then alternates between decreasing and increasing parts. Two different interpretations are possible. On the one hand, we could argue that time matters per se and that theoretical models should thus investigate the role of duration as a potential factor affecting optimal exchange rate policy. On the other hand, one may argue that we have not controlled for every possible time-varying variable. This alternative view would imply that time may not matter after all, and that we have simply omitted important covariates. We cannot 


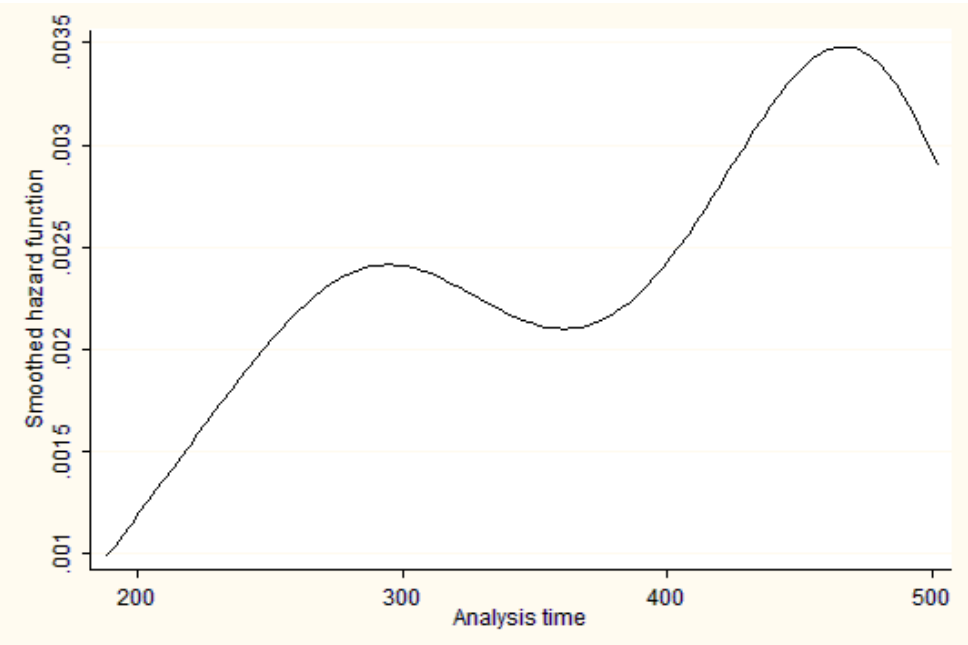

Figure 5: Baseline hazard function, proportional hazard model

state which of these two views is correct. One possible extension would be to take account of unobserved heterogeneity explicitly, so as to control for the effect of omitted variables. Time would matter whenever the estimated baseline hazard function still remains different from a horizontal line. We leave this issue for further research.

\section{Concluding remarks}

This paper studies the conditional probability of an exit from a fixed exchange rate regime. When we believe that the time spent within a regime is an important determinant of the probability of exiting this regime, the natural view of exits emphasizes conditional probabilities instead of unconditional ones and duration models are an appropriate tool.

We use both non-parametric and semi-parametric techniques to obtain estimates of the hazard functions. The application of the non-parametric Kaplan-Meier estimator uncovers significant non-monotonic patterns of duration dependence that differs across types of countries. To the extent that duration dependence may be driven by time-varying covariates, we also estimate a semi-parametric proportional hazard specification by partial maximum likelihood. Having controlled for macroeconomic, financial and institutional variables, we conclude that the pattern of duration dependence remains non-monotonic. 
Therefore, it seems that the time spent within a regime is itself a significant determinant of the probability of an exit.

The issue of duration dependence deserves further investigation. Firstly, the results obtained from the estimation of the proportional hazard specification can be interpreted in two ways. On the one hand, we can argue that the time spent within a peg matters. On the other hand, we could also claim that we have not controlled for every possible timevarying explanatory factor, so that the pattern of duration dependence persists because of omitted variables. We believe that this problem should be studied further by introducing more explanatory variables, and by taking explicit account of unobserved heterogeneity.

Secondly, this paper aggregates all possible types of fixed exchange rate regimes into a single category. It is doubtful, however, that hard pegs such as dollarization or currency boards exhibit the same properties as soft target zones or even moving bands of fluctuation. Therefore, the analysis should be refined by disaggregating fixed exchange rate regimes into several categories. In turn, this would increase the number of possible exits between regimes. We could study exits from hard fixing to soft fixing, soft fixing to hard fixing, hard fixing to floating, and soft fixing to floating. In turn, we could also focus on exits from floating regimes. There are several possible combinations of exits and these may exhibit different patterns of duration dependence. Disaggregating across finer categories of exchange rate regimes would also allow for a discussion of the bipolar hypothesis in terms of duration dependence. In this paper, the aggregation of all types of fixing strategies within a single category implies that we can only study one corner solution, the move towards floating exchange rates.

Finally, we have ignored a potential problem of selection bias. Some of the factors that affect the duration of an exchange rate regime may also affect the decision to enter such a regime in the first place. For example, high inflation could possibly lead a country to adopt a rigidly fixed exchange rate within the scope of a broader disinflation strategy. The evolution of the rate of inflation during the peg will also affect the duration of this arrangement. The study of selection bias in the context of duration models is still in its infancy and we leave this aspect for further investigation. 


\section{References}

[1] Asici, A., Wyplosz, C., 2003. The art of gracefully exiting a peg. The Economic and Social Review 34, 211-228.

[2] Beck, T., Demirguc-Kunt, A., Levine, R., 1999. A new database on financial development and structure. World Bank Policy Research Working Paper 2146.

[3] Blomberg, S., Frieden, J., Stein, E., 2004. Sustaining fixed rates: the political economy of currency pegs in Latin America. Manuscript.

[4] Bubula, A., Otker-Robe, I., 2002. The evolution of exchange rate regimes since 1990: evidence from de facto policies. IMF Working Paper 155.

[5] Calvo, G., Reinhart, C., 2002. Fear of floating. The Quarterly Journal of Economics 117, 379-408.

[6] Detragiache, E., Mody, A., Okada, E., 2005. Exits from heavily managed exchange rate regimes. IMF Working Paper 39.

[7] Duttagupta, R., Otker-Robe, I., 2003. Exits from pegged regimes: an empirical analysis. IMF Working Paper 147.

[8] Eichengreen, B., Rose, A., Wyplosz, C., 1995. Exchange market mayhem: the antecedents and aftermath of speculative attacks. Economic Policy 21, 249-312.

[9] Ghosh, A., Gulde, A., Wolf, H., 2002. Exchange Rate Regimes, Choices and Consequences. MIT Press, Cambridge.

[10] Husain, A., Mody, A., Rogoff, K., 2005. Exchange rate regime durability and performance in developing versus advanced economies. Journal of Monetary Economics 52, $35-64$.

[11] Kaminsky, G., Lizondo, S., Reinhart, C., 1998. Leading indicators of currency crises. IMF Staff Papers 45, 1-48. 
[12] Kiefer, N., 1988. Economic duration data and hazard functions. Journal of Economic Literature 26, 646-679.

[13] Klein, M., Marion, N., 1997. Explaining the duration of exchange-rate pegs. Journal of Development Economics 54, 387-404.

[14] Levy-Yeyati, E., Sturzenegger, F., 2005. Classifying exchange rate regimes: deeds vs. words. European Economic Review 49, 1603-1635.

[15] Masson, P., Ruge-Murcia, F., 2003. Explaining the transition between exchange rate regimes. CIREQ Working Paper 15.

[16] Meissner, C., 2002. A new world order: explaining the emergence of the classical gold standard. NBER Working Paper 9233.

[17] Reinhart, C., Rogoff, K., 2004. The modern history of exchange rate arrangements: a reinterpretation. Quarterly Journal of Economics 119, 1-48.

[18] Setzer, R., 2004. The political economy of exchange rate regime duration: a survival analysis. Manuscript, University of Hohenheim.

[19] Shambaugh, J., 2004. The effect of fixed exchange rates on monetary policy. The Quarterly Journal of Economics 119, 301-352.

[20] Sosvilla-Rivero, S., Maroto-Illera, R., Perez-Bermejo, F., 2002. An electic approach to currency crises: drawing lessons from the EMS experience. FEDEA Working Paper 22.

[21] Tudela, M., 2004. Explaining currency crises: a duration model approach. Journal of International Money and Finance 23, 799-816. 


\section{Appendix: Explanatory variables}

Inflation: International Financial Statistics, IMF, line 64.

GDP growth: World Development Indicators, World Bank.

Openness: sum of exports and imports divided by gross domestic product. World Development Indicators, World Bank.

Current account balance: ratio to gross domestic product. World Development Indicators, World Bank.

Overall budget balance: ratio to gross domestic product. World Development Indicators, World Bank.

Unemployment rate: Economic Outlook, OECD; International Financial Statistics, IMF, line 67.

Real effective exchange: average monthly growth. Ghosh, Gulde and Wolf (2002).

Banking crisis: dummy variable. Ghosh, Gulde and Wolf (2002).

International reserves: International Financial Statistics, IMF, line 1L.

Financial development: liquid liabilities of the entire financial sector relative to gross domestic product. Beck, Demirguc-Kunt and Levine (1999).

Central bank independence: rate of governor turnover per five years, Ghosh, Gulde and Wolf (2002).

Political rights: Freedom in the World survey, Freedom House.

Capital controls: binary index. Ghosh, Gulde and Wolf (2002). 